\title{
Instrução Programada no ensino de conteúdos químicos: atividade desenvolvida na Residência Pedagógica
}

\section{Programmed Instruction in the teaching of chemical contents: activity developed in the Pedagogical Residency}

\author{
Renan Martins Libório ${ }^{1 *}$, Esthefany Guedes Coitim $^{1}$, Steve Pereira Manickchand ${ }^{1}$, Yana \\ Bárbara da Silva Teixeira ${ }^{1}$, Sidilene Aquino de Farias ${ }^{1}$.
}

\begin{abstract}
RESUMO
O presente trabalho teve como objetivo investigar como os estudantes do Ensino Médio percebem e engajam-se numa atividade didática de Instrução Programada. Essa estratégia de ensino e aprendizagem foi desenvolvida por quatro licenciandos em Química numa disciplina do Estágio Curricular integrada ao Programa Residência Pedagógica (RP), na Universidade Federal do Amazonas, consistindo em uma atividade de intervenção planejada conjuntamente escola-universidade, a partir da tríade licenciandopreceptor-docente universitário. Para tanto, as atividades foram desenvolvidas em duas escolas parceiras, colaboradoras na RP. Os dados foram registrados no diário de campo e coletados a partir de uma folha de atividades, que fazia parte das sequências didáticas dos quatro licenciandos, sendo respondida por 253 estudantes do Ensino Médio de duas escolas estaduais públicas, localizadas no município de Manaus-AM e, posteriormente, analisados mediante a técnica Análise de Conteúdo. Os resultados mostraram que os estudantes são pouco habituados com estratégias de ensino e aprendizagem diferente daquelas utilizadas no ensino tradicional. Observou-se que o primeiro contato dos estudantes, com conteúdo considerados abstratos e difíceis, a partir do instrumento possibilitou bom aproveitamento na aprendizagem, pois os estudantes foram capazes de entender conceitos chaves que podem ser aprofundados em aulas posteriores.
\end{abstract}

Palavras-chave: Ensino Médio, Instrução Programada, Estudantes, Ensino de Química.;

\section{ABSTRACT}

This study aimed to investigate how High School students perceive and engage in a specific didactic activity in Programmed Instruction. Four undergraduate Chemistry students developed this teaching and learning strategy during the Curricular Teaching Practice articulated to the Pedagogical Residency Program (PR) at the Federal University of Amazonas. The activity was an intervention activity planned by the school and university based on the triad undergraduate student - educator - university professor. Therefore, the activities were developed in two partner schools that collaborate in the Pedagogical Residency. The data was recorded in field diaries and generated according to a Programmed Instruction activity sheet, which part of the didactic sequences developed by the four undergraduate students. Two hundred and fifty-three (253) High School students from two public schools in Manaus - AM filled in the activity sheet. The data was later on analyzed according to the Content Analysis technique. The results demonstrate that the students were not quite familiar with teaching and learning strategies different from those used in traditional teaching. It was observed that the first contact students had with contents considered abstract and difficult, using the planned instrument provided good learning, as students could understand key concepts that could be studied in depth in later lessons.

\footnotetext{
${ }^{1}$ Universidade Federal do Amazonas.

*E-mail: renan_martinn@outlook.com
} 
Keywords: High school, Students, Programmed Instruction, Chemistry teaching.

\section{INTRODUÇÃO}

Nos anos de 1930, os cursos de licenciatura eram organizados no modelo " $3+1$ ", ou seja, três anos semelhante ao curso bacharelado, e mais um ano de disciplinas pedagógicas. Esse modelo de currículo prevaleceu até 1960, sob muitas críticas, pois claramente era identificada a separação dos saberes específicos pedagógicos. Assim, depreende-se que o modelo de professor tecnicista não se apresenta adequado para a formação docente, visto que um bom professor, além de dominar o conhecimento específico de sua área de formação, precisa de vários conhecimentos que se relacionam ao processo de ensino e aprendizagem (PEREIRA, 1999).

A partir dos anos 2000, as normativas legais têm buscado superar o referido modelo da formação inicial de professores, propondo outro eixo curricular que visa integrar teoria e prática, Prática como Componente Curricular e, bem como a ampliação da carga horária Estágio Curricular, com mínimo de 400 horas, que deve iniciar a partir da segunda metade do curso (BRASIL, 2001, 2019).

Nesse sentido, este trabalho decorre da vivência e reflexão de um grupo de graduandos do curso de Licenciatura em Química, que estavam desenvolvendo atividades vinculadas às disciplinas do Estágio Curricular integradas ao Programa Residência Pedagógica. Vale enfatizar que assumimos a importância da integração teoria e prática, a partir da vivência em contextos educacionais reais, como possibilidade de desenvolver atividades didáticas fundamentadas teoricamente, de maneira consciente.

Com isso, entendemos que as aprendizagens possam ser desenvolvidas mesmo diante dos limites dessas atividades, bem como, das interferências contextuais, numa perspectiva de regulação das aprendizagens dos estudantes. Do exposto, apresentamos reflexões sobre uma das atividades desenvolvidas com os estudantes do Ensino Médio, que consiste na Instrução Programada, sendo este método ${ }^{2}$ fundamentada em Teorias Comportamentalistas.

\footnotetext{
${ }^{2}$ No decorrer do artigo vamos nos referir a Instrução Programada como atividade, visto que consistiu em uma etapa das sequências didáticas desenvolvidas.
} 


\section{FORMAÇÃO INICIAL DO PROFESSOR DE QUÍMICA E RESIDÊNCIA PEDAGÓGICA}

Gatti (2013) relaciona a realidade do ensino contemporâneo com a formação dos novos professores, sendo assim, foi possível encontrar na literatura científica diversos que direcionam seus objetivos para estudos sobre o processo formativo dos estudantes nas licenciaturas (MELO, 1999; FARIAS; FERREIRA, 2012; XAVIER, 2020). Segundo Melo (1999) a formação dos professores deve seguir as diretrizes educacionais do país, como: Lei de Diretrizes e Bases da Educação Nacional (LDB), Parâmetros Curriculares Nacionais (PCN) e Base Nacional Comum Curricular (BNCC), dessa maneira o mesmo se tornará um profissional apto a lecionar corretamente utilizando metodologias alternativas que englobam a todos os alunos, levando em conta todo contexto econômico, social, cultural, dentre outros fatores importantíssimos que envolvem o ensinar.

Farias e Ferreira (2012), ao estudarem a formação inicial de professores de Química na Região Norte do Brasil, apontaram diferentes olhares acerca dos conhecimentos na formação dos futuros professores de Química, mencionando que estudantes do Ensino Médio valorizam os conhecimentos pedagógicos para formação desse profissional. Em outra perspectiva, tendo um aspecto mais específico na formação inicial do professor de Química, o estudo de mestrado de Xavier (2020) buscou investigar o preparo de licenciandos formandos para atuarem de maneira interdisciplinar em aulas de Química no Ensino Médio, sendo observado aproximações das suas concepções com aquelas apresentadas na literatura, porém dificuldades em construírem atividades didáticas interdisciplinares.

A partir disso, destaca-se que a participação de licenciandos em programas como a Residência Pedagógica pode contribuir para maior aproximação da escola com a universidade e, por conseguinte, possibilitar maior integração das atividades vivenciadas pelos licenciandos permitindo desenvolver práticas educativas que abordem diversas estratégias de ensino e aprendizagem, promovendo a superação da dicotomia entre teoria e prática.

É importante mencionar que a Coordenação de Aperfeiçoamento de Pessoal de Nível Superior (Capes), desde 2007 passou a fomentar a formação inicial e continuada de professores para a Educação Básica. Tal atribuição foi consolidada pelo Decreto $\mathrm{n}^{\mathrm{o}}$ 6.755, de 29 de janeiro de 2009, que instituiu a Política Nacional de Formação de 
Profissionais do Magistério da Educação Básica, portanto havendo parcerias com as Secretárias de Ciência e Tecnologia e as Secretárias de Educação dos estados, para incentivar cada vez mais uma política educacional na ampliação do acesso ao saber e do fornecimento de ideias inovadoras aos problemas encontrados na Educação Nacional, bem como uma qualificação na formação de professores da educação básica.

Entre as diversas ações da Capes de assegurar uma educação de qualidade, inaugurou recentemente o Programa da Residência Pedagógica (RP) - uma das ações que integram a Política Nacional de Formação de Professores - que tem por objetivo contribuir no aperfeiçoamento da formação prática nos cursos de licenciatura. Dentre as principais metas da RP, podemos citar: a) Aperfeiçoar a formação dos discentes de cursos de licenciatura, por meio do desenvolvimento de projetos que fortaleçam o campo da prática e conduzam o licenciando a exercitar de forma ativa a relação entre teoria e prática profissional docente, utilizando coleta de dados e diagnóstico sobre o ensino e a aprendizagem escolar, entre outras didáticas e metodologias; b) Induzir a reformulação da formação prática nos cursos de licenciatura, tendo por base a experiência da residência pedagógica (CAPES, 2020).

Em um primeiro momento, a RP propõe que o licenciando desenvolva atividades de ambientação, que visa habituar do futuro docente no ambiente escolar. A partir da tomando de consciência do contexto real, o licenciando irá analisar diversos contextos diferentes, como também refletir sobre a utilização de diversas metodologias de ensino e aprendizagem. Além dessas atividades, outras demandas são solicitadas do professor na escola e que consiste em saberes formativos necessários para os futuros professores: lançamento de notas, regência, organização, participação de eventos, entre outras. Para possibilitar a reflexão e integração entre teoria e prática algumas atividades podem ser desenvolvidas na Instituição de Educação Superior (IES), como: elaboração de diários reflexivos, leitura e debate de teóricos educacionais, construção de sequências didáticas, entre outras (ZABALA, 1998; ZABALZA, 2004; GIORDAN; GUIMARÃES; MASSI, 2011).

\section{COMPREENSÃO DA APRENDIZAGEM NA PERSPECTIVA}

\section{COMPORTAMENTALISTA}

No ano de 1950 diversos estudos foram levantados em relação ao comportamento humano em vários ambientes, incluindo o escolar, destacando-se o behaviorismo ou comportamentalismo. Compreendida como a teoria das decisões 
humanas, em que essas poderiam ser afetadas ou modificadas por diversos comportamentos ou ações. Ressalta-se que diversos estudiosos nessa corrente teórica, como: Pavlov, Watson e Guthrie, Thorndike e Hull e Skinner (LEITE, 2018).

O teórico e psicólogo Skinner desenvolveu uma Teoria Comportamentalista Condicionamento Operante - que se manteve firme por diversos períodos do desenvolvimento da sociedade:

“[...] Para o Behaviorismo, explicar um fenômeno significa demonstrar sua funcionalidade, ou seja, demonstrar sob que condições e com quais características, que mudanças no ambiente resultam nele, numa busca de compreender por que fazemos, e o que devemos e não devemos fazer [...]" (PILETTI; ROSSATO, 2011, p. 14).

Com o passar dos anos, teorias passaram por mudanças, destacando-se a Teoria Comportamental atualizada, proposta por Abraham Maslow, que se refere ao indivíduo na forma pessoal e individual, tratando os campos da motivação de forma hierárquica. Ao trazer a teoria para o campo da educação, pode-se verificar que a atividade do docente em sala de aula, precisa levar em conta todo o contexto em que os alunos/escolas estão inseridos, tendo em vista resultar em um ensino mais adequado para todos (CORREA et al., 2007). Na Figura 1 têm-se a escala das necessidades que devem ser levadas em consideração no contexto da sala de aula:

Figura 1 - Hierarquia das necessidades de Maslow.

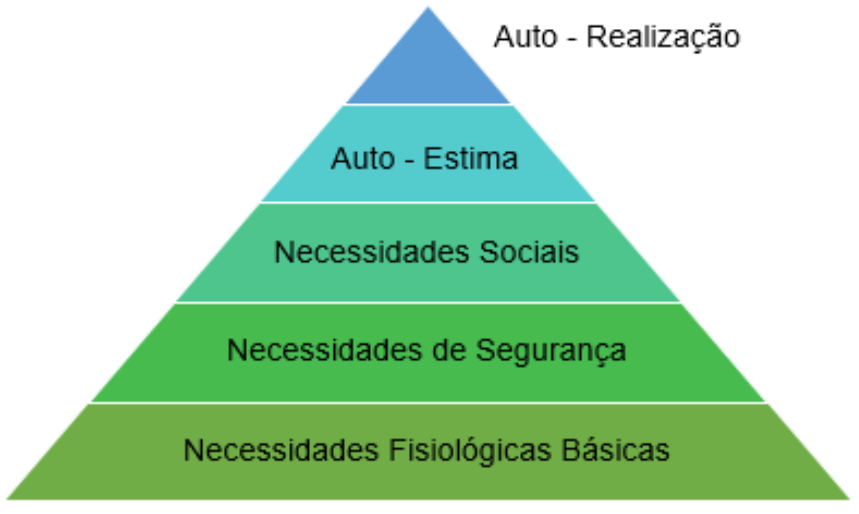

Fonte: Correa et al. (2007).

Nessa escala, pode-se observar que as variáveis pertencentes, correspondem ao aluno de forma individual, o que conduz a pensar que os professores precisam levar em consideração no momento de ensinar as necessidades sociais desses alunos, observar a autoestima dos alunos dentre outros fatores. $\mathrm{Na}$ base da pirâmide temos as necessidades 
Fisiológicas Básicas, nesse tópico se enquadra o descanso do aluno, conforto físico, dentre outros fatores básicos que influenciam na aprendizagem.

No topo da pirâmide está a autorrealização, responsável pela tomada de decisões, diversidade, autonomia etc., encontra-se no topo pelo fato de ser um fator primordial em atividades em sala de aula. Quando um professor realiza uma avaliação, este procura obter um retorno do aprendizado dos alunos. Nesse momento, o estudante precisa tomar decisões e muita das vezes encontra-se sozinho, precisando de autonomia para realizar a devida atividade (FERREIRA; DEMUTTI; GIMENEZ, 2010).

Para que haja sempre um desenvolvimento no processo de interação turma/professor, é preciso estimular os alunos com palavras, atitudes, gestos dentre outras maneiras possíveis para criar vínculos de confiança, dessa maneira os estudantes irão se tornar mais ativos durante as aulas. Consoante a isto, é dever do professor criar um ambiente favorável para criação de novas sínteses dos alunos, como também o desenvolvimento social em atividades (VASCONCELOS; PRAIA; ALMEIDA, 2003).

Sendo algo mais individual, uma característica de muitos desses métodos alternativos ao ensino tradicional, consiste que eles são de ritmo próprio e, o estudante prossegue para o próximo tópico conforme compreende o anterior. A Instrução Programada, com base em teorias comportamentalistas, é um recurso muito útil e de fácil uso no qual o estudante é responsável por sua autoinstrução; é um reforçador de aprendizagem do aluno, cabendo ao professor buscar contingências de reforço, como forma do aluno buscar a resposta necessária (KURBANOGLU; TASKESENLIGIL; SOZBILIR, 2005).

Consiste em um quadro com texto dividindo o conteúdo em pequenas partes e cada parte possui lacunas que os alunos devem preencher, e que podem imediatamente após isto, conferir a resposta as quais estão presentes no próximo quadro ou até mesmo no próprio enunciado da questão apresentada de maneira oculta, mas que são facilmente verificadas. Na Instrução Programada o que se busca é a aprendizagem de conceitos principais, desta maneira as perguntas não precisam ser altamente complexas, fazendo com que assim as chances de sucesso possam aumentar, visto que, “[...] ao preencher corretamente uma lacuna, o aluno se sente reforçado e, portanto, estimulado a continuar desenvolvendo o programa" (MOREIRA, 1999, p. 60).

O professor deve preparar uma Instrução Programada de fácil compreensão, haja vista que a elaboração da pergunta, pode influenciar na resposta do aluno. Pois, quando 
este responde uma pergunta de fácil compreensão, o professor além de trilhar o caminho do aprendizado ao aluno facilita a resposta correta, portanto ao responder corretamente a pergunta, o estudante se sente reforçado, capacitado a querer responder mais questões.

Pesquisas utilizando este recurso em aulas de Química mostram que alunos respondem de forma melhor, quando comparado a aulas apenas expositivas e tradicionais. Kurbanoglu, Taskesenligil, Sozbilir (2005) aplicaram uma Instrução Programada no ensino de Estereoquímica e sugerem que esta é uma abordagem melhor baseados na taxa de sucesso que obtiveram. Wangila, Martin e Ronald (2015) também fizeram uso deste instrumento em conjunto com abordagens convencionais para explicar a estrutura do átomo e a tabela periódica obtendo alto índice de sucesso por ser centrada no aluno e permitir o melhor desenvolvimento de conteúdos abstratos.

Nessa perspectiva, objetivou-se investigar como os estudantes do Ensino Médio percebem e engajam-se em uma atividade didática de Instrução Programada. É importante ressaltar que, o desenvolvimento dessa atividade na escola visou que os futuros professores sejam aptos para utilizar dos mais variados instrumentos e teorias para proporcionar uma educação de qualidade.

\section{PERCURSO METODOLÓGICO}

Este estudo pauta-se no enfoque Qualitativo de Pesquisa, pois busca compreender como os estudantes engajam-se em uma atividade didática consistindo numa coleta de dados sem medição numérica, tendo em vista aprimorar perguntas de pesquisa no processo de interpretação. Em relação aos dados qualitativos, destaca-se que são descrições detalhadas de situações, eventos, pessoas, interações, condutas observadas e suas manifestações (HERNÁNDEZ; FERNÁNDEZ; BAPTISTA, 2013). A esse respeito, salienta-se que o evento em que a atividade de pesquisa está relacionada, consiste em uma ação do Subprojeto Química do Programa Residência Pedagógica conjuntamente com a disciplina de Estágio Supervisionado, de uma IES da Região Norte do Brasil.

$\mathrm{Na}$ Pesquisa Qualitativa na coleta de dados utiliza-se técnicas como a observação não estruturada, entrevistas abertas, revisão de documentos, discussão em grupo, entre outras (HERNÁNDEZ; FERNÁNDEZ; BAPTISTA, 2013). Diante disso, elaborou-se uma Instrução Programada que foi aplicada a 253 estudantes do Ensino Médio, de duas escolas estaduais públicas situadas no município de Manaus. Enfatiza-se que cada licenciando-residente elaborou uma Instrução Programada em suas respectivas 
sequências didáticas, considerando os conteúdos e séries conforme o Quadro 1. Os instrumentos foram elaborados adaptando-se alguns modelos da literatura, segundo os seguintes princípios básicos: 1) Pequenas etapas; 2) Resposta ativa; 3) Verificação imediata; 4) Ritmo próprio; 5) Teste do programa (MOREIRA, 1999).

Quadro 1 - Planejamento e aplicação das Instruções Programadas.

\begin{tabular}{|c|c|c|c|c|c|c|}
\hline SD & Temática & Conteúdo & Esc. & Série & Quan. & Apl. \\
\hline 1 & Materiais no cotidiano & $\begin{array}{c}\text { Ligações covalentes e } \\
\text { energia }\end{array}$ & \multirow{2}{*}{$\mathrm{E}_{1}$} & $1^{a}$ & 44 & \multirow{2}{*}{ Individual } \\
\hline 2 & $\begin{array}{l}\text { Decomposição da } \\
\text { camada de ozônio }\end{array}$ & $\begin{array}{l}\text { Reações de } \\
\text { Substituição }\end{array}$ & & $3^{a}$ & 102 & \\
\hline 3 & $\begin{array}{l}\text { Danos causados pelo } \\
\text { consumo excessivo de } \\
\text { refrigerantes }\end{array}$ & Soluções & \multirow{2}{*}{$\mathrm{E}_{2}$} & $2^{a}$ & 79 & \multirow{2}{*}{$\begin{array}{l}\text { Duplas e } \\
\text { trios }\end{array}$} \\
\hline 4 & $\begin{array}{l}\text { Conservantes e } \\
\text { decomposição de } \\
\text { alimentos }\end{array}$ & Cinética Química & & $2^{a}$ & 28 & \\
\hline \multicolumn{7}{|c|}{ Total de participantes } \\
\hline
\end{tabular}

Legendas: SD: Sequência Didática; Esc.: escola; Quan.: Quantidade de alunos; Apl.: forma de aplicação.

Fonte: elaborado pelos autores.

O modelo utilizado teve como estrutura a divisão do texto, de modo que havia lacunas a serem preenchidas relacionadas aos conceitos principais começando "[...] com o conhecimento inicial do aluno e, em pequenas etapas, avançam para uma meta final de aprendizado" (KURBANOGLU; TASKESENLIGIL; SOZBILIR, 2005, p. 16). Após responder a primeira pergunta, o aluno passa para a próxima, que possui ao seu lado a resposta da questão anterior, como pode ser observado na Figura 2.a, para então, chegar na última ficha com uma mensagem parabenizando o aluno pelo término da atividade com sucesso (Figura 2b), a qual seria o reforço positivo. 
Figura 2. (a) Esquema da instrução programada sobre Cinética Química; (b) Última ficha da Instrução Programada sobre Soluções.

(a)

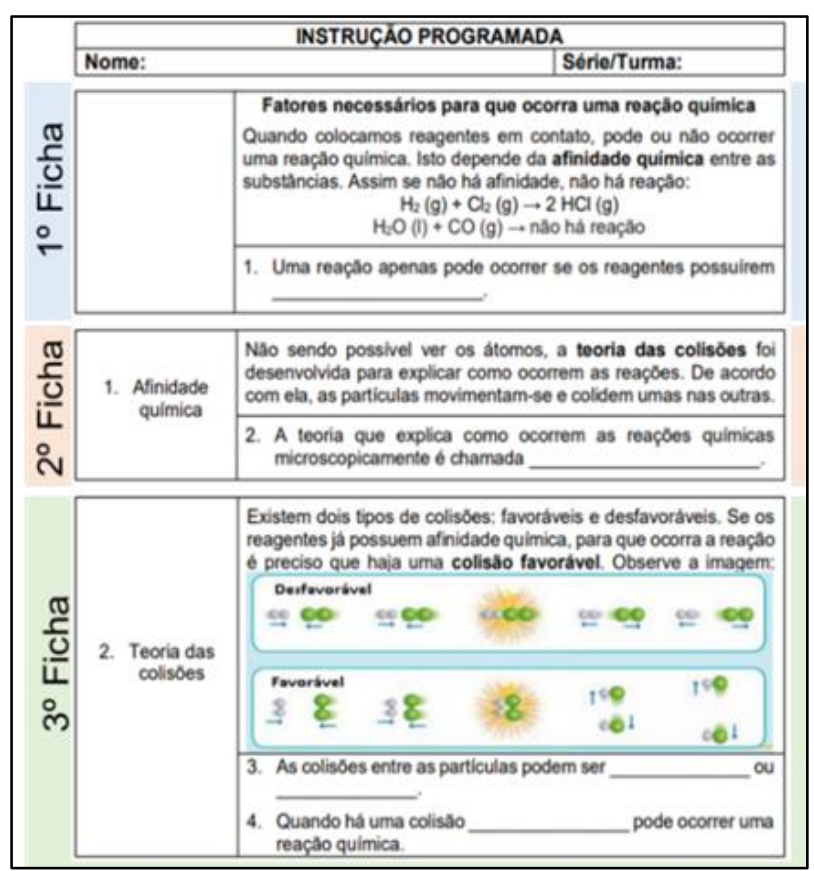

(b)

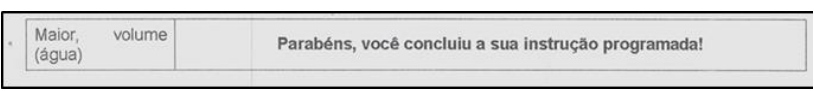

Fonte: elaborado pelos autores.

Destaca-se que além dos dados obtidos na IP, também foi realizada uma entrevista não estruturada para alguns alunos, tendo como finalidade obter informações sobre a percepção dos estudantes relativas ao momento da realização da Instrução Programada.

Na análise dos dados utilizou-se a técnica Análise de Conteúdo (BARDIN, 2009), que tem como foco inicial a mensagem seja ela verbal, gestual, silenciosa, figurativa, documental, ou ainda, diretamente provocada. Enfatiza-se que a mensagem expressa um significado e um sentido, sendo estes vinculados às condições contextuais - econômicas e socioculturais - em que os emissores estão inseridos, tais comunicações são socialmente construídas e possuem componentes cognitivos, afetivos, valorativos, ideológicos.

\section{RESULTADOS E DISCUSSÕES}

Conforme mencionado anteriormente, as Instruções Programadas foram desenvolvidas em diferentes momentos das sequências didáticas, de cada licenciandoresidente, sendo elaboradas para diferentes conteúdos: Ligações covalentes e Energia; 
Reações de substituição; Soluções; e Cinética Química. A partir das fichas com as atividades e da observação realizada durante o desenvolvimento da atividade, verificouse o envolvimento e compromisso dos estudantes com a atividade. A partir da entrevista não estruturada foram observadas as percepções dos estudantes sobre a atividade.

\section{Engajamento dos Estudantes no Desenvolvimento da Atividade}

Ao analisar as observações registradas sobre as aulas, verificou-se que os alunos são pouco habituados com diversidade de métodos. Todavia, na maioria das turmas a maior parte dos estudantes demonstrou interesse pelo novo instrumento, mesmo que houvesse figuras e gráficos que pudessem complementar na aprendizagem - Interesse por atividades diferentes.

Ressalta-se que a IP foi apresentada aos estudantes como uma atividade comum e obrigatória, visto que em alguns casos, a aplicação foi realizada em um contexto pouco favorável, como perto do horário de saída ou de ir para o refeitório - conflito com necessidades fisiológicas e de socialização.

Após a organização da sala, percebeu-se que os estudantes terminaram rapidamente, em média 30 minutos, o que já era esperado, como evidenciado por Barbato (1968):

"É possível observar quando se aplica uma instrução programada em uma sala de aula, que os estudantes são estimulados a responder essas questões, de tal maneira que terminam rapidamente de responder as perguntas, isto é impressionante e, chega a ser, até questionador, se realmente eles aprenderam ou se apenas copiaram do colega ao lado" (BARBATO,1968, p. 2).

Melo e Leonardo (2019) mencionam que um dos problemas que afetam o Ensino Médio consiste na frequente queixa dos professores acerca da falta de interesse dos estudantes em seus estudos. Por outro lado, é comum ouvir dos estudantes que eles não sabem por que razão devem estudar determinados conteúdos. Considerando este contexto, observou-se que alguns estudantes demoraram para responder e não perceberam que as respostas estavam inseridas no próprio texto da atividade - Baixo interesse pela atividade.

Retomando a ideia do Interesse por atividades diferentes, os estudantes, que reconheceram a lógica da atividade, podem passar a impressão de que não realizaram a síntese esperada e que apenas copiaram a resposta, pois a resposta estava próxima e disponível - Identificação da lógica da atividade. Contudo, foi observado que alguns 
responderam a atividade da forma correta e justa, pois foram constatadas respostas de interpretação própria e não cópia da resposta disponível, ou ainda, a identificação pelos próprios alunos de haverem errado a resposta, isso pode ser observado, respectivamente, nas respostas da Instrução Programada sobre o conteúdo "Soluções" (Figuras 3a e 3b), em que os alunos do Grupo 2 escreveram "grande" e não "maior" (resposta sugerida na ficha) e os alunos do Grupo 5 identificaram as respostas que erraram e corrigiram.

Figura 3 - (a) respostas do Grupo 2 que demonstram elaboração própria dos alunos; (b) respostas do Grupo 5 que demonstram a identificação e correção do erro.

(b)

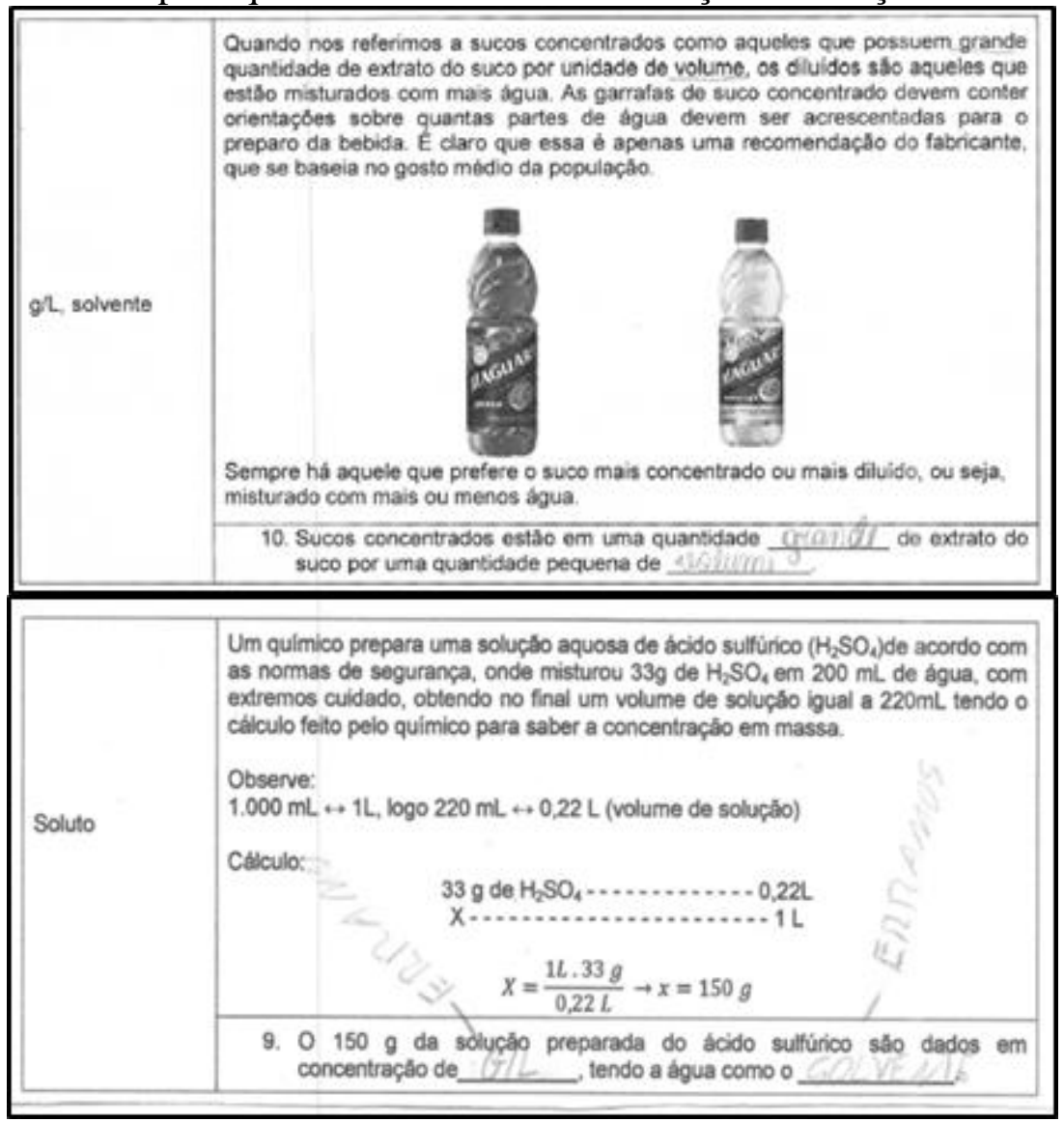

Além disso, foi possível observar que os estudantes realizaram leitura da atividade e não somente copiaram as respostas corretas, visto que responderam a partir da leitura que realizaram em cada item da IP, como pode ser observado, na IP sobre o conteúdo "Soluções" (Figura 4). Isso demonstrou o compromisso dos estudantes com a atividade, que pode envolver a autorrealização, motivação e/ou interesse pela atividade, entre outros, mas que possibilita desenvolvimento cognitivo (FERREIRA; DEMUTTI; GIMENEZ, 2010; FONSÊCA, 2016). Ressalta-se que foram observadas no decorrer da atividade, situações de cópia e desinteresse dos alunos, porém quando o assunto foi retomado pelo professor, os alunos já possuíam uma base de conhecimento 
proporcionada pela IP, inclusive lembravam de algumas das palavras chaves para conceitos. A partir disso, pode-se inferir que o reforço das respostas corretas, elogio ao final da atividade, podem contribuir e facilitar a aprendizagem (VASCONCELOS; PRAIA; ALMEIDA, 2003).

Figura 4 - Resposta dos estudantes Grupo 3 que demonstram envolvimento na leitura dos enunciados na Instrução Programada.

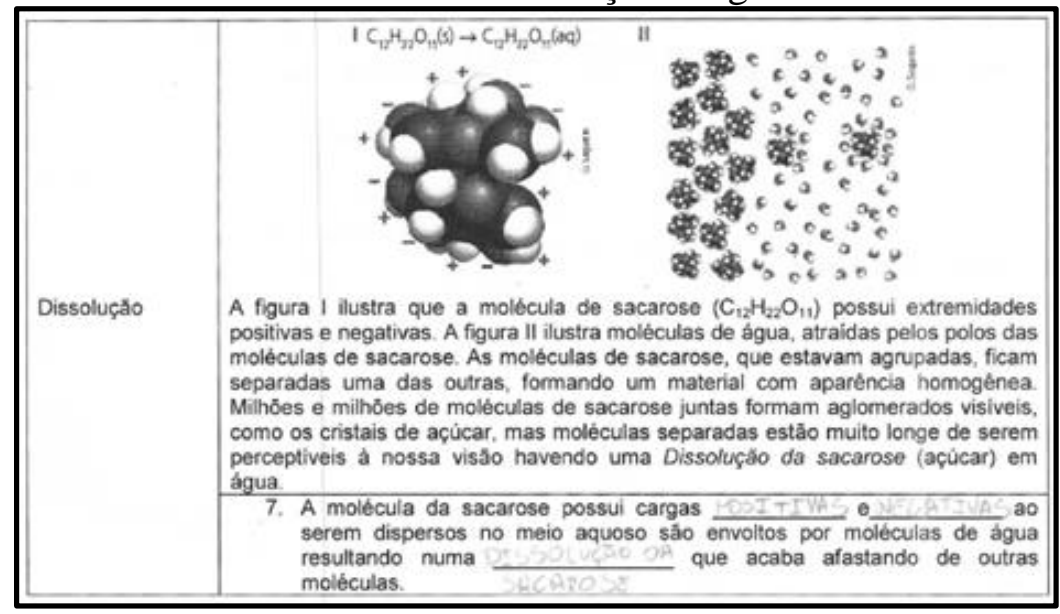

É importante salientar que ao deparar-se com o conteúdo novamente em sala, os alunos já possuem dúvidas específicas e são participativos, justamente por terem uma ideia mais clara do que está sendo explanado. Nesse momento, entra o papel do professor de conseguir mediar o conhecimento, guiando os alunos para uma compreensão mais aprofundada dos conceitos e suas relações (KURBANOGLU; TASKESENLIGIL; SOZBILIR, 2006).

Consequentemente, este recurso possibilitou um primeiro contato com o conteúdo de forma mais compreensível para o aluno, visto que tiveram a possibilidade de prosseguir no seu tempo, permanecendo mais na leitura dos conceitos que se mostraram mais complexos, e assim, foram ativos na construção do conhecimento por se auto instruir, como um estudo dirigido. Além disso, foi possível observar que na continuidade do conteúdo químico, como na sequência didática que contemplou Reações de Substituição, que os alunos conseguiram relacionar os conteúdos anteriores, como nitração, com o novo, reações de halogenação.

\section{Percepções dos Estudantes sobre a Instrução Programada}

Buscou-se conhecer a percepção dos estudantes sobre a atividade, em que manifestaram que a atividade foi divertida e fácil, promovendo autorrealização desses estudantes visto que demonstraram satisfação na realização da atividade (FERREIRA; 
DEMUTTI; GIMENEZ, 2010; FONSÊCA, 2016). Destaca-se ainda que a atividade promoveu, de certo modo, satisfação em saber que a resposta estava certa ao comparar com a resposta disponível, assim como felicidade ao chegar ao final da atividade e ver que realizou a atividade com sucesso.

"Então eu achei bem divertido é... A forma como você trabalhou com a gente e colocando a resposta atrás, dá aquela sensação de... Será que eu acertei ou será que eu errei e assim [...]" (Aluno B).

"Tipo de assim... de felicidade por ter concluído uma atividade completa" (Aluno C).

A utilização desse método mostrou-se como uma novidade para os estudantes, pois compararam a atividade com um jogo e mencionaram ser interessante a utilização de recurso de multimídia para a aplicação da IP, uma vez que se parece muito com fases de um jogo, só que em fichas com assuntos referentes à Química, conforme relatou o Aluno A. A esse respeito, atualmente, com a disponibilidade de diversas multimídias, o professor pode criar instruções programadas utilizando o celular ou computador, com imagens e reforço de parabéns ou elogios motivacionais quando o aluno acertar a questão (WANGILA; MARTIN; RONALD, 2015).

"Foi, mas a gente só passa de fase se a gente respondesse. Não tem como, mas se fosse realizado no computador a gente só passava de fase se respondesse" (Aluno A).

E ainda, o Aluno A quando questionado sobre o que achou da atividade, salientou ter sido uma atividade interessante, sendo uma síntese de tudo que foi estudado em sala de aula: Tipo interessante, tipo meio que o conteúdo que você está dando foi tudo o que a gente já sabe praticamente [...] Meio que um resumão (Aluno A). Isso decorreu da compreensão do licenciando-residente que entendeu haver a necessidade de ministrar uma aula expositiva anterior para aprendizagem de conceitos, enquanto o momento da Instrução Programada seria apenas uma tarefa e não uma estratégia de ensino e aprendizagem. Contudo, o estudante mostrou-se motivado e envolvido com a IP.

Por fim, a participação dos alunos foi interessante, sendo receptivos com a atividade, por ser nova e ser fornecida a resposta, fazendo com que não houvesse dúvidas sobre a resposta certa, sentindo-se à vontade por, talvez, imaginar que 
receberiam nota pelo quantitativo de acerto e erro dessa atividade. É importante mencionar que a atividade deixou os alunos bem ativos no processo de aprendizagem, pois eles mesmos verificavam se erraram ou não. Conforme destacado por Moreira (1999), os alunos se sentem reforçado e estimulado a continuar desenvolvendo a atividade proposta.

\section{CONSIDERAÇÕES FINAIS}

Aponta-se que em relação ao engajamento, os alunos, em maioria, comprometeram-se com na realização da Instrução Programada, pois realizaram uma atividade diferente das habituais aulas expositivas. Nesse sentido, a literatura científica corrobora este estudo, visto que foram alcançados resultados positivos na aprendizagem das turmas participantes, enfatizando também a contribuição para o desenvolvimento da autonomia do aluno e na construção do seu conhecimento (KURBANOGLU; TASKESENLIGIL; SOZBILIR, 2005; WANGILA; MARTIN; RONALD, 2015). Destaca-se ainda que, percebeu-se a mudança de comportamento em aulas expositivas, após o uso da IP, devido a maior participação dos alunos. A partir disso, pode-se depreender que seja por ter ocorrido um primeiro contato com o conteúdo e sentirem-se mais seguros e estimulados.

É importante enfatizar que o fato de disponibilizar a resposta, pode levar alguns alunos à apenas copiar a resposta sem preocupar-se com a leitura e o seu aprendizado. A esse respeito, uma forma para evitar que ocorra a "cola", ou ainda, que os estudantes busquem ler os enunciados das perguntas, o professor poderia entregar uma ficha de cada vez, ou seja, um quadro de cada vez, então na medida em que os estudantes concluem uma ficha (uma questão), eles podem solicitar que o professor lhes forneça a próxima ficha. Outro formato seria apresentar as respostas apenas no final, isso poderia contribuir no envolvimento dos alunos com o texto e sua interpretação. Ou ainda, conforme sugerido por um aluno utilizar recursos de multimidia.

O uso de diferentes metodologias e recursos consiste em uma habilidade que o professor precisa desenvolver, sendo então de suma importância entrar em contato e utilizá-las ainda na formação inicial (LABURÚ; ARRUDA; NARDI, 2003). O Programa Residência Pedagógica juntamente com a disciplina Estágio Supervisionado foi o espaço curricular para os residentes vivenciarem diferentes metodologias, em que ocorreu a participação de quatro residentes no desenvolvimento da Instrução Programada, pautada a partir de pressupostos teóricos de Skinner na sua teoria 
comportamentalista, em turmas de Ensino Médio. Sublinha-se que a atividade possibilitou a integração entre teoria e prática educativa na vivência dos futuros professores de Química.

Os graduandos, entrando em contato com a realidade escolar, puderam perceber erros no momento de aplicação da atividade que podem ser melhorados e, posteriormente, colaborem ainda mais para o processo de ensino e aprendizagem. Podendo ser desenvolvido até mesmo pelo prolongamento de parceria entre IES e instituição de ensino básico. Além disso, se reconhece a Instrução Programada como um recurso que pode ser utilizado em conjunto com diferentes abordagens até mesmo a tradicional, possibilitando uma base ou revisão de conteúdos abordados; ou talvez o desenvolvimento de forma aprimorada deste recurso utilizando novas tecnologias, sempre considerando o contexto em que estão inseridos os alunos.

\section{AGRADECIMENTOS}

Às gestões escolares, professores de Química e alunos participantes do estudo.

À Capes.

\section{REFERÊNCIAS}

BARBATO, M. G. Instrução Programada. Revista da Escola de enfermagem da USP, v. 2, n. 1, p. 28-38, 1968.

BARDIN, L. Análise do conteúdo. Tradução: Luís Antero Reto e Augusto Pinheiro. 1a ed. São Paulo: Edições 70, 2011.

BRASIL. Ministério da Educação. Parecer CNE/CP no 28, de 8 de maio de 2001. Brasília, DF: MEC/CNE, 2001. Disponível em: <http://portal.mec.gov.br/sesu/ arquivos/pdf/02801formprof.pdf>. Acesso em: 13/11/2021.

BRASIL. Ministério da Educação. Resolução CNE/CP No 2, de 20 de dezembro de 2019. Brasília, DF: MEC/CNE, 2019. Disponível em: < http://portal.mec.gov.br/ docman/dezembro-2019-pdf/135951-rcp002-19/file>. Acesso em: 13/11/2021.

CAPES. Coordenação de Aperfeiçoamento de Pessoal de Nível Superior. Programa de Residência Pedagógica. Disponível em: <https://www.capes.gov.br/educacao-basica/ programa-residencia-pedagogica $>$. Acesso em: 31/01/2020.

CORREA, E. C; SILVA, M. R. D; SANTOS, V. S; OLIVEIRA, E. A. A. Q. Teorias de motivação humana: uma análise dos artigos publicados no ENANPAD entre 2004 e 2007. In: ENCONTRO LATINO-AMERICANO DE INICIAÇÃO CIENTÍFICA. 12. ENCONTRO LATINO AMERICANO DE PÓS-GRADUAÇÃO, 8. 2008. São José dos Campos, 2008. Anais [...] São José dos Campos: Univap, 2008. p. 1-4. 
FARIAS, S. A.; FERREIRA, L. H. Diferentes olhares acerca dos conhecimentos necessários na formação inicial do professor de Química. Química Nova, v. 35, n. 4, p.844-850, 2012.

FERREIRA, A; DEMUTTI, C. M; GIMENEZ, P. E. O. A Teoria das Necessidades de Maslow: A Influência do Nível Educacional Sobre a sua Percepção no Ambiente de Trabalho. In: Seminários em Administração (SemeAd). 13. 2010. Anais [...] São Paulo: FEAUSP, 2010. p. 2 -14.

FONSÊCA, P. N. da; LOPES, B. J.; PALITOT, R. M.; ESTANISLAU, A. M.; COUTO, R. N.; COELHO, G. L. H. Engajamento escolar: explicação a partir dos valores humanos. Psicologia Escolar e Educacional, v. 20, n. 3, p. 611-620, 2016.

GATTI, A. B. Educação, escola e formação de professores: políticas e impasses. Educar em Revista, v. 1, n. 50, p. 51-67, 2013.

GIORDAN, M.; GUIMARÃES, Y. A. F.; MASSI, L. Uma análise das abordagens investigativas de trabalhos sobre Sequências didáticas: tendências no ensino de ciências. In: Encontro Nacional de Pesquisa em Educação em Ciências, 8, 2011. Anais [...] Campinas: Unicamp, 2011. p. 1-13.

HERNÁNDEZ, S. R.; FERnÁNDEZ, C. C.; BAPTISTA L. M. P. Metodologia de pesquisa. Tradução: Daisy Vaz de Moraes. 5ª ed., Porto Alegre: Penso, 2013.

KURBANOGLU, N. I.; TASKESENLIGIL, I.; SOZBILIR, M. Programmed instruction revisited: a study on teaching stereochemistry. Chemistry Education Research and Practice, v. 7, n. 1, p. 13-21, 2006.

LABURÚ, E. C; ARRUDA, M. S; NARDI, R. Pluralismo metodológico no ensino de ciências. Ciência \& Educação, v. 9, n. 2, p. 247-260, 2003.

LEITE, B. S. Tecnologias no Ensino de Química: teoria e prática na formação docente. $1 \underline{a}$ ed., Curitiba: Editora Appris, 2018.

MELO, L. C. B.; LEONARDO, N. T. S. Sentido do ensino médio para estudantes de escolas públicas. Psicologia Escolar e Educacional. v. 23, p. 1-9, 2019.

MELO, M. T. L. Programas oficiais para formação dos professores da educação básica. Educação \& Sociedade. v. 20, n. 68, p. 46-58. 1999.

MOREIRA, M. A. Teorias de Aprendizagem. São Paulo: Editora pedagógica e universitária,1999.

PEREIRA, J. E. D. As licenciaturas e as novas políticas educacionais para a formação docente. Educação \& Sociedade, v. 20, n. 68, p. 109-125,1999.

PILETTI, N; ROSSATO, S. M. Skinner condicionamento e aprendizagem. In:

Psicologia da aprendizagem: da teoria do condicionamento ao construtivismo. São Paulo: Editora Contexto, p. 13-33, 2011. 
VASCONCELOS, C; PRAIA, F. J; ALMEIDA, S. L. Teorias de aprendizagem e o ensino/aprendizagem das ciências: da introdução à aprendizagem. Psicologia Escolar e Educacional. v. 7, n. 1, p. 15-17, 2003.

WANGILA, M. J.; MARTIN, W.; RONALD, M. Effect of Programmed Instruction on Students' Attitude Towards Structure of the Atom and the Periodic Table among Kenyan Secondary Schools. Science Education International, v. 26, n. 4, p. 488-500, 2015.

XAVIER, L. R. Interdisciplinaridade na Formação Inicial de Professores de Química: Perspectivas e Desafios para a Prática Educativa. 2020. 132 f. Dissertação (Mestrado em Ensino de Ciências e Matemática). Instituto de Ciências Exatas, Universidade Federal do Amazonas, Manaus, 2020.

ZABALA, A. A prática educativa: como ensinar. Porto Alegre: Artmed Editora S.A., 1998.

ZABALZA, M. Diários de Aula: um instrumento de pesquisa e desenvolvimento professional. Porto Alegre: Artmed, 2004. 